\title{
Nanoselenium transformation and inhibition of cadmium accumulation by regulating the lignin biosynthetic pathway and plant hormone signal transduction in pepper plants
}

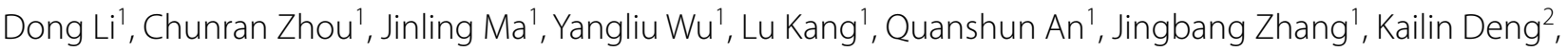
Jia-Qi Li ${ }^{1 *}$ and Canping Pan ${ }^{1 *}$

\begin{abstract}
Selenium (Se) can promote the growth and resistance of agricultural crops as fertilizers, while the role of nanoselenium (nano-Se) against Cd remains unclear in pepper plants (Capsicum annuum L.). Biofortification with nanoSe observably restored $\mathrm{Cd}$ stress by decreasing the level of $\mathrm{Cd}$ in plant tissues and boosting the accumulation in biomass. The Se compounds transformed by nano-Se were primarily in the form of SeMet and MeSeCys in pepper tissues. Differential metabolites and the genes of plant signal transduction and lignin biosynthesis were measured by employing transcriptomics and determining target metabolites. The number of lignin-related genes (PAL, CAD, 4CL, and COMT) and contents of metabolites (sinapyl alcohol, phenylalanine, $p$-coumaryl alcohol, caffeyl alcohol, and coniferaldehyde) were remarkably enhanced by treatment with $\mathrm{Cd} 1 \mathrm{Se} 0.2$, thus, maintaining the integrity of cell walls in the roots. It also enhanced signal transduction by plant hormones and responsive resistance by inducing the biosynthesis of genes (BZR1, LOX3, and NCDE1) and metabolites (brassinolide, abscisic acid, and jasmonic acid) in the roots and leaves. In general, this study can enable a better understanding of the protective mechanism of nano-Se in improving the capacity of plants to resist environmental stress.
\end{abstract}

Keywords: Nanoselenium, Cd stress, Lignin biosynthetic pathway, Plant hormone signal transduction, Pepper plants

\section{Introduction}

Heavy metal pollution in soil has become a global problem. The increase in absorption of $\mathrm{Cd}$ can lead to changes in plant metabolism, which limit crop productivity and pose a substantial threat to the environment. Concerns about the effects of $\mathrm{Cd}$ stress on crop physiology and biochemistry, the synthesis of plant primary and secondary metabolites, and even on the quality of agricultural

\footnotetext{
*Correspondence: jiaqili@cau.edu.cn; canpingp@cau.edu.cn 1 Innovation Center of Pesticide Research, Department of Applied Chemistry, College of Science, China Agricultural University, Beijing 100193, China

Full list of author information is available at the end of the article
}

products are widely expressed [1]. Existing research shows that the effects of $\mathrm{Cd}$ stress on crops are closely related to the organic matter in soil, cation exchange capacity, $\mathrm{pH}$, soil microorganisms, secondary metabolites, crop species, and stage of growth [2]. The effects of $\mathrm{Cd}$ on different growth stages of crops have been studied using foliar sprays and polluted soil to evaluate the changes in crop physiology, biochemistry, enzymes, and non-enzymatic antioxidant systems. He et al. [3] have shown that $\mathrm{Cd}$ damages the metabolic function of plants by affecting photosynthesis and respiration, the absorption of nutrients and water, cell division, nitrogen metabolism, and the expression of proteins. Javed et al. [4] found that excessive $\mathrm{Cd}$ affects the activities of enzymes original author(s) and the source, provide a link to the Creative Commons licence, and indicate if changes were made. The images or other third party material in this article are included in the article's Creative Commons licence, unless indicated otherwise in a credit line to the material. If material is not included in the article's Creative Commons licence and your intended use is not permitted by statutory regulation or exceeds the permitted use, you will need to obtain permission directly from the copyright holder. To view a copy of this licence, visit http://creativecommons.org/licenses/by/4.0/. The Creative Commons Public Domain Dedication waiver (http://creativeco mmons.org/publicdomain/zero/1.0/) applies to the data made available in this article, unless otherwise stated in a credit line to the data. 
related to the Calvin cycle and carbohydrate metabolism, thereby inhibiting the growth of maize. Cd stress in plants stimulates the formation of reactive oxygen species (ROS), which cause protein oxidation, induce damage to lipids and nucleic acids, and change the metabolism of carbohydrates [5]. Therefore, Cd stress can affect the growth of crops by reducing photosynthesis and the synthesis of nutrients and may also regulate the synthesis of secondary metabolites through oxidative mechanisms.

Pepper fruits are rich in sugars, amino acids, vitamins, carotenoids, capsaicinoids, organic acids, flavonoids, phenolic acids, and volatile metabolites [6]. These metabolites determine the color, nutrition, and flavor of the pepper fruit, as well as its health functions, such as antioxidative, lipid-lowering, and anti-inflammatory properties. Capsaicinoids, which are unique to pepper, have useful clinical applications, including anti-cancer, analgesic, and health care effects [7]. The accumulation and transfer of metals in vegetables depend on environmental factors and plant genotypes. Vegetables easily take up heavy metals and accumulate them in their edible parts [8]. These compounds accumulate in different tissues and transform into a harmful composition of the food chain. Thus, it is highly important to research the effect of $\mathrm{Cd}$ stress on plant primary and secondary metabolites in peppers.

Plants are constantly faced with various types of infections in their growth, and a series of defense mechanisms have been formed during the long-term process of evolution. Exogenous stimulating factors, such as phytohormones, nanoengineering materials, and trace elements among others, have been widely studied in many crops for their ability to regulate plant growth and enhance the resistance of plants to stress $[9,10]$. Javed et al. [4] found that exuded organic acids improve the absorption of nutrients and increase the content of antioxidant enzymes, such as superoxide dismutase (SOD) and peroxidase (POD), thereby increasing the tolerance of corn to $\mathrm{Cd}$. $\mathrm{Xu}$ et al. [11] found that biochar can reduce the accumulation of $\mathrm{Cd}$ in pepper roots that had been subjected to a low level of $\mathrm{Cd}$. The content of malondialdehyde decreased in the improved soil, and the content of chlorophyll increased significantly. Yan et al. [12] found that low concentrations of methyl jasmonate $(0.1 \mu \mathrm{mol} / \mathrm{L})$ can increase the contents of antioxidant enzymes (SOD, POD, and ascorbate peroxidase (APX) and jasmonic acid (JA), which reduce the harmful effects of $C d$ stress on pepper plants. Guo et al. [13] showed that treatment with $\mathrm{Cd}$ $(100 \mathrm{mg} / \mathrm{kg})$ and $\mathrm{Si}(400 \mathrm{mg} / \mathrm{kg})$ positively correlated with the increased secretion of phenolic compounds in the rhizosphere. The exudation and accumulation of phenolic substances in plant tissues can alleviate $\mathrm{Cd}$ stress by chelating heavy metals or resisting oxidative damage. In addition, nanomaterials can penetrate plant cell walls to enter the plant and promote the healthy growth of plants by regulating the expression of related genes. Different nanomaterials have a substantial potential to reduce the toxicity of $\mathrm{Cd}$ but have no obvious negative effects on the growth of tomatoes, cucumbers, lettuce, and carrots [14].

Selenium, as a beneficial element for plant growth, promotes the growth of plants by increasing the accumulation of carbohydrates and plant hormones, which has attracted extensive research on the protection of plants from biotic and abiotic stresses. Se resulted in the production of low-mobility $\mathrm{Cd}$ compounds and increased the ability of cell walls to bind exogenous compounds in canola plants. It can reduce the level of $\mathrm{Cd}$ in the roots, affect the transportation of $\mathrm{Cd}$ to the stem, and further ameliorate the accumulation of $\mathrm{Cd}$ in the seed [15]. Liu et al. [16] suggested that organic amendments and Se promote the conversion of soil $\mathrm{Cd}$ from a bioavailable form to an immobilized one, thereby reducing the level of $\mathrm{Cd}$ in cereals. Se $(5 \mu \mathrm{M})$ alleviated the $\mathrm{Cr}$ and methylglyoxal-induced oxidative damages and phytotoxicity by enhancing essential amino acids, antioxidants, and the glyoxalase system in Brassica napus L. [17]. It is effective at reducing the toxicity of heavy metals and limiting the absorption and translocation of heavy metals in plants. Se can also activate antioxidant enzymes and improve photosynthesis to quench the production of reactive oxygen species (ROS) under heavy metal conditions. However, the exact mechanism of secondary metabolism that results in the induction of tolerance to Cd stress by Se has not yet been elucidated. To date, various studies have elaborated the impact of Se on growth, primary metabolites, distribution and morphology, antioxidant systems, secondary compounds, and plant hormones $[18,19]$. However, to our knowledge, there has not been a systematic study on the effect of nano-Se on the relationship of plant hormones and phenylpropanoid metabolism, particularly on the metabolites in the lignin synthesis pathway of pepper plants under Cd stress.

In our study, the growth, root ultrastructure, saccharide compounds, and Se speciation were determined, and we explored the changes in these indices using different concentrations of nano-Se in pepper plants under $\mathrm{Cd}$ stress. The key differential metabolites and genes of the lignin biosynthetic pathway and signal transduction by plant hormones were screened utilizing transcriptomics and measuring the levels of target metabolites. The related signal regulatory network was constructed to reveal the mechanism of intervention of nano-Se in the alleviation of $\mathrm{Cd}$ stress. 


\section{Materials and methods}

\section{Plant cultivation and experimental conditions}

Hydroponic experiments were performed in a greenhouse at China Agricultural University, Beijing, China. It was conducted under the following conditions: $25 / 15^{\circ} \mathrm{C}$

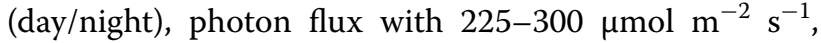
and a 14/12 h (light/dark) photoperiod with 75-80\% humidity. Pepper seeds (Capsicum annuum L.) were germinated while watered with deionized water for 7 days. Uniform and healthy seedlings were transplanted into a plastic pot $(2 \mathrm{~L})$ and cultured in Hoagland-Arnon nutrient solution [20]. A half-strength nutrient solution was supplied for three days, and a full-strength solution was used until harvest. The solution was continuously refilled and renewed every two days to ensure an adequate supplementation of nutrition. The plants were pretreated in the nutrient solution for 10 days.

Se $(0,0.2$, and $1 \mathrm{mg} / \mathrm{L})$ and $\mathrm{Cd}(0$ and $1 \mathrm{mg} / \mathrm{L})$ were added to the vessel in form of $\mathrm{Cd}^{2+}$ in water/medium: $5 \%$ nitric acid $(1000 \mathrm{mg} / \mathrm{L})$ and nano-Se. The nano-Se was characterized as previously described [21]. The experiment was established with five repetitions of the six treatments that included Cd0Se0, Cd0Se0.2, Cd0Se1, Cd1Se0, Cd1Se0.2, and Cd1Se1. Samples were collected following continual treatment for 7 days. The roots were immersed in a $20 \mathrm{mmol} / \mathrm{L}$ solution of EDTA- $\mathrm{Na}_{2}$ for $5 \mathrm{~min}$ to remove the residual metal ions on the root surface. These plants were divided into roots, stems, and leaves after they were washed with deionized water. Some samples were used to determine the elements and metabolites. A portion of the samples was stored at $-80{ }^{\circ} \mathrm{C}$ for transcriptomics and the determination of genes.

\section{Analyses of saccharide compounds}

The samples $(20 \mathrm{mg})$ were extracted with $1 \mathrm{~mL}$ of ultrapure water. The mixed solution was subjected to ultrasound for $30 \mathrm{~min}$ and then centrifuged for $10 \mathrm{~min}$ at $14,000 \mathrm{rpm}$. All of the supernatant was filtered with a $0.1 \mu \mathrm{m}$ injection syringe. The liquid was then diluted 20 times with ultrapure water. The concentration of saccharide compounds was determined using a Thermo Scientific Dionex ICS $-5000^{+}$ion chromatograph (Waltham, MA, USA). It was equipped with an SP single pump, EG eluent generator, AS-AP automatic sampler, DC electrochemical detector, and Chromeleon7.2 SR5 chromatographic data analytical software. The flow rate was 1 $\mathrm{mL} / \mathrm{min}$, and the injection volume was $10 \mu \mathrm{L}$. Ultrapure water and $200 \mathrm{mM} \mathrm{NaOH}$ (50\% of $\mathrm{NaOH}$ was diluted with ultrapure water) were used as mobile phases $\mathrm{A}$ and $\mathrm{B}$, respectively. The gradient elution procedure was as follows: $91 \%$ A, 0 min; 91\% A, $18 \mathrm{~min}$; 0\% A, $21 \mathrm{~min}$; 0\% A, $31 \mathrm{~min}$; 91\% A, $32 \mathrm{~min}$; and 91\% A, $40 \mathrm{~min}$.

\section{Transmission electron microscopy}

The roots were merged in a $2.5 \%(\mathrm{v} / \mathrm{v})$ solution of glutaraldehyde for $2 \mathrm{~h}$ at $4{ }^{\circ} \mathrm{C}$. They were washed twice with phosphate-buffered saline (PBS, pH 7.2-7.4) at $4{ }^{\circ} \mathrm{C}$ for $15 \mathrm{~min}$. The samples were added to $1 \%(\mathrm{v} / \mathrm{v}) \mathrm{OsO} 4$ at $4{ }^{\circ} \mathrm{C}$ for $2 \mathrm{~h}$ and washed three times with PBS. The solution was dehydrated in a series of acetone solutions. Concentrations of $50 \%, 70 \%, 80 \%$, and $90 \%$ of acetone were used to treat the samples for $15 \mathrm{~min}$. The samples were treated twice with $100 \%$ of acetone for $10 \mathrm{~min}$. The mixed solution was immersed overnight in the resin. It was polymerized at a high temperature and cut into slices of approximately $70 \mathrm{~nm}$ using a Lycra slicer (EM UC6; Leica, Wetzlar, Germany), dyed with uranyl acetate for $15 \mathrm{~min}$, and treated with lead citrate for $10 \mathrm{~min}$. The samples were dried and then photographed using a transmission electron microscope (TEM) (H-7650; JEOL. Ltd., Tokyo, Japan).

\section{Analysis of total selenium and cadmium}

A mixed solution of $\mathrm{HNO}_{3}$ and $\mathrm{HClO}_{4}(9: 1, \mathrm{v} / \mathrm{v})$ was added to digest the plant root, stem, and leaf samples. They were diluted to $50 \mathrm{~mL}$ by adding deionized water into a volumetric flask. The supernatant was determined using atomic absorption spectrometry (HG-AFS; Haiguang, China) equipped with a hydride generation system to determine the concentration of $\mathrm{Cd}$ and $\mathrm{Se}$ in different tissues.

\section{Analysis of selenium speciation}

One gram of the pepper tissues (roots, stems, and leaves) were hydrolyzed using $2 \mathrm{~mL}$ of Tris- $\mathrm{HCl}(75 \mathrm{mmol} / \mathrm{L}, \mathrm{pH}$ 7.5)and $5 \mathrm{mg} / \mathrm{mL}$ of protease XIV (Sigma-Aldrich, St. Louis, MO, USA) at $37{ }^{\circ} \mathrm{C}$. Finally, the supernatant was filtered through a $0.22-\mu \mathrm{m}$ filter membrane. The samples were then subjected to high-performance liquid chromatography inductively coupled plasma mass spectrometry (HPLC-ICP-MS; SA-50, Thermo Scientific iCAP RQ).

The HPLC system was equipped with a Hypersil Gold $\mathrm{C}_{8}$ column $(4.6 \times 250 \mathrm{~mm}, 5 \mu \mathrm{m}$; Thermo, USA). A volume of $20 \mathrm{mM} \mathrm{KH}_{2} \mathrm{PO} 4$ that contained $0.5 \%$ heptafluorobutyric acid and methanol were used as mobile phases $\mathrm{A}$ and $B$, respectively. The flow rate was set at $1.0 \mathrm{~mL} / \mathrm{min}$. The gradient elution procedure was as follows: 100\% A, 3 min; 95\% A, $3.1 \mathrm{~min}$; 95\% A, $14 \mathrm{~min}$; 100\% A, $14.1 \mathrm{~min}$; and $100 \% \mathrm{~A}, 15.0 \mathrm{~min}$. The mass spectrometer conditions were as follows: the radio-frequency power was $1550 \mathrm{~W}$; the plasma gas flow rate was $14 \mathrm{~L} / \mathrm{min}$; the flow rate of carrier gas was $1.06 \mathrm{~L} / \mathrm{min}$; the flow rate of auxiliary gas flow was $0.8 \mathrm{~L} / \mathrm{min}$; the dwell time was $0.1 \mathrm{~s}$, and the analysis mass number was $78 \mathrm{Se}$. Five standard selenoamino acids were used in this experiment and included 
the following: $\mathrm{Se}(\mathrm{IV})$ (selenite), Se(IV) (selenite), SeCys (selenocysteine), MeSeCys (methylselenocysteine), and SeMet (selenomethionine) purchased from the National Institute of Metrology for Certified Reference Materials, Beijing, China.

\section{Plant hormone analyses}

The method is a modification of previous research [22]. The roots and leaves were ground to a powder in liquid nitrogen. The samples $(0.1 \mathrm{~g})$ were then subjected to $1 \mathrm{~mL}$ of extraction solution that contained methanol: water: formic acid (80:19:1, v/v/v) using ultrasound for $10 \mathrm{~min}$. They were centrifuged for $5 \mathrm{~min}$ at $12,000 \mathrm{rpm}$. These supernatants were added to $50 \mathrm{mg}$ of primary secondary amine (CNW Technologies $\mathrm{GmbH}$, Shanghai, China) in a $2 \mathrm{~mL}$ centrifuge tube. The mixed solution was dried with nitrogen, and the volume was kept constant to 100 $\mu \mathrm{L}$ with an aqueous solution of $80 \%$ methanol. All of the supernatant was filtered using a $0.22-\mu \mathrm{m}$ organic membrane. An Agilent 6465 Triple Quadrupole UPLC-MS/ MS (Ultivo; Agilent Technologies, Santa Clara, CA, USA) was equipped with an EclipsePlus C18 column $(2.1 \times 50$ $\mathrm{mm}, 1.8 \mu \mathrm{m})$. The flow rate was $0.4 \mathrm{~mL} / \mathrm{min}$. Acetonitrile and $0.1 \%$ formic acid in water were used as mobile phases $A$ and $B$, respectively. The gradient elution procedure was as follows: $80 \% \mathrm{~A}, 0 \mathrm{~min}$; $5 \% \mathrm{~A}, 4 \mathrm{~min} ; 80 \% \mathrm{~A}$, $4.1 \mathrm{~min}$, and $80 \% \mathrm{~A}, 5.2 \mathrm{~min}$. It used positive and negative ion scanning mode and multiple reaction monitoring (MRM). All the parameters of MRM and collision energy (Additional file 1: Table S1) were optimized for maximum selectivity and sensitivity.

\section{Determination of the metabolites related to lignin synthesis}

A total of $0.1 \mathrm{~g}$ of roots was ground to a powder in liquid nitrogen. The samples were extracted using $1 \mathrm{~mL}$ of an aqueous solution of $80 \%$ methanol (1\% formic acid). These mixtures were shaken for $3 \mathrm{~min}$, treated with an ultrasonic instrument for $10 \mathrm{~min}$ and centrifuged at $10,000 \mathrm{rpm}$ for $5 \mathrm{~min}$. The supernatant was added to a $2 \mathrm{~mL}$ centrifuge tube filled with $50 \mathrm{mg}$ of $\mathrm{C} 18$ and $5 \mathrm{mg}$ of multiwalled carbon nanotubes (MWCNTs) purchased from the Sinopharm Chemical Reagent Co. (Beijing, China). They were vortexed for $2 \mathrm{~min}$ and centrifuged for $5 \mathrm{~min}$ at $10,000 \mathrm{rpm}$ at $4^{\circ} \mathrm{C}$. All the supernatant was filtered using a $0.22-\mu \mathrm{m}$ organic membrane.

An Agilent 6465 Triple Quadrupole UPLC-MS/MS (Ultivo, Agilent Technologies) was equipped with a Venusil Hilic $(2.1 \times 50,1.8 \mu \mathrm{m})$. The flow rate was 0.25 $\mathrm{mL} / \mathrm{min}$. Acetonitrile and $0.1 \%$ formic acid water were used as mobile phases A and B, respectively. The gradient elution procedure was as follows: $5 \% \mathrm{~A}, 0 \mathrm{~min}$; 95\% A, 4 min; 5\% A, $4.1 \mathrm{~min}$; and 5\% A, $5.2 \mathrm{~min}$. It used positive and negative ion scanning mode and MRM. All the parameters of MRM and collision energy (Additional file 1: Table S2) were optimized for maximum selectivity and sensitivity.

The HPLC-UV (Agilent Technologies) was equipped with a Venusil Hilic $(4.6 \times 100,5 \mu \mathrm{m})$. The flow rate was $1 \mathrm{~mL} / \mathrm{min}$. Acetonitrile and ultrapure water were used as mobile phases A and B, respectively. The compounds were eluted from a $5 \mathrm{~min}$ isocratic run at a 60:40 ratio of $A$ to $B$. The UV absorption was monitored at $217 \mathrm{~nm}$.

\section{mRNA expression analysis Transcriptome sequencing}

The roots and leaves were stored at $-80{ }^{\circ} \mathrm{C}$ and then used with an RNAprep pure Plant Kit (Tiangen Biotech, Beijing, China) to extract the total RNA following the manufacturer's instructions. The concentration of RNA in different tissues was measured using an RNA Nano 6000 Assay Kit (Thermo Fisher Scientific, Wilmington, DE, USA). The Agilent Bioanalyzer 2100 system to assess the integrity of RNA (Agilent Technologies). A NEBNext Ultra ${ }^{\text {TM }}$ RNA Library Prep Kit for Illumina (NEB, Beverly, MA, USA) was used to generate sequencing libraries following the manufacturer's recommendations, and index codes were added to the attribute. EdgeR was used to perform an analysis of the differential expression of two samples. Significant differential expression was established as the threshold for the Fold Change $\geq 1.5$ and $P<0.01$. The GOseq $R$ packages based on Wallenius non-central hyper-geometric distribution implemented Gene Ontology (GO) enrichment analysis of the differentially expressed genes (DEGs) that adjusted for gene length bias in the DEGs. A pathway enrichment analysis was performed using KOBAS software to test the statistical enrichment of DEGs in the Kyoto Encyclopedia of Genes and Genomes (KEGG) pathways.

\section{Real-time quantitative PCR}

Ten representative genes were selected to verify the transcriptomics results using quantitative real-time reverse transcriptase-PCR (qRT-PCR). The RNA extraction utilized an RNAprep pure Plant Kit according to the manufacturer's instructions. The cDNA synthesis used a FastQuant RT Kit. The qRT-PCR was performed with SuperReal PreMix Plus (SYBR Green). The expression of the $\beta$-actin served as a reference. The primers for sequences (Additional file 1: Table S3) were purchased from Sangon Biotech (Shanghai, China). The specific methods used were previously described [22]. 

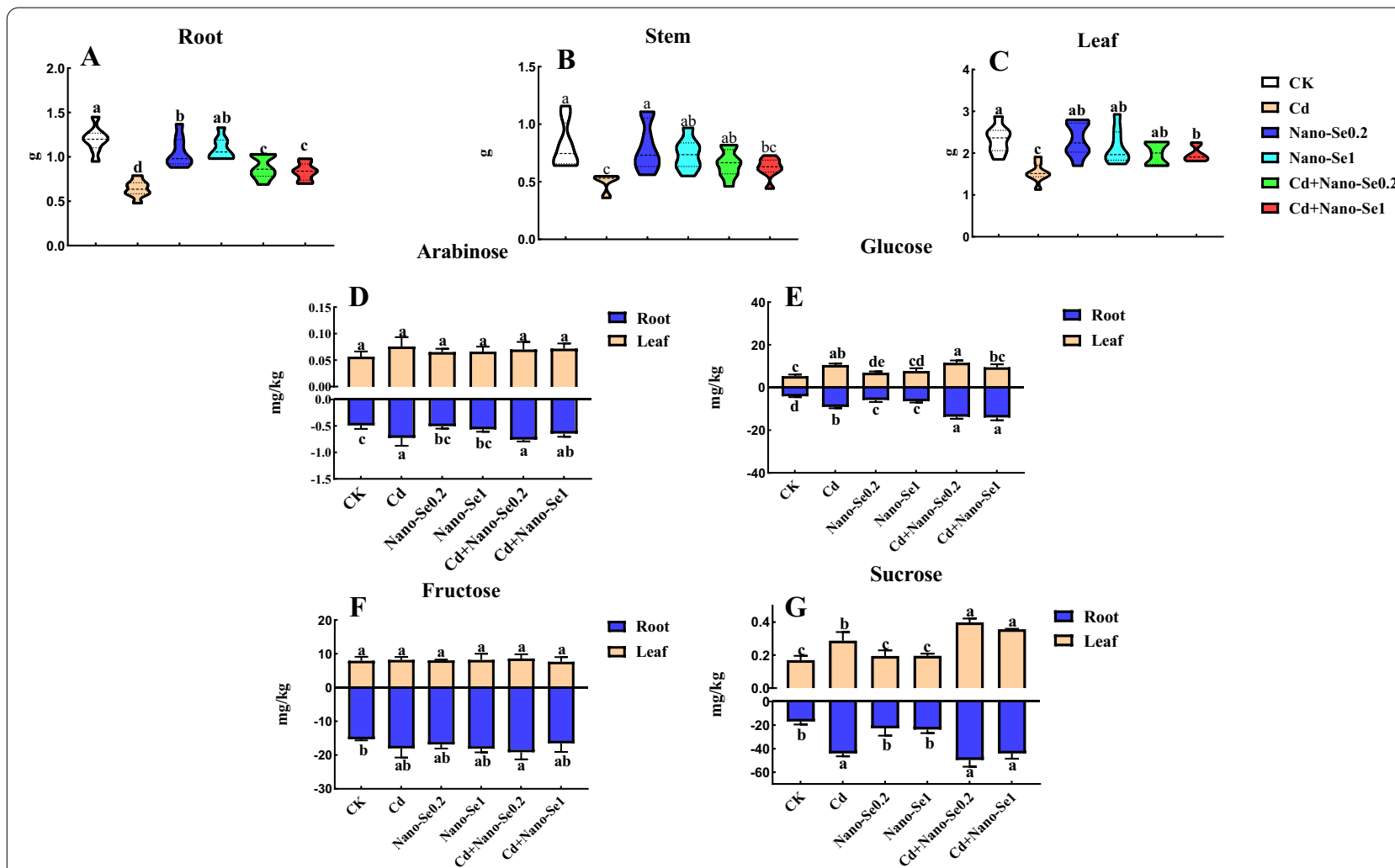

Fig. 1 Effect of the interaction of nanoselenium (nano-Se) and cadmium (Cd) on the biomass and saccharides of pepper plants. The effects of different ratios of nano-Se $(0,0.2$, and $1 \mathrm{mg} / \mathrm{L})$ and $\mathrm{Cd}(0$ and $1 \mathrm{mg} / \mathrm{L})$ on the biomass $(\mathbf{A}-\mathbf{C})$, arabinose $(\mathbf{D})$, glucose $(\mathbf{E})$, fructose $(\mathbf{F})$, and sucrose $(\mathbf{G})$ in the leaves and roots of pepper plants. Different letters across treatments indicate significant differences at $P<0.05$

\section{Statistical analysis}

A difference analysis was performed by a one-way analysis of variance (ANOVA) using SPSS 26.0 (IBM, Inc., Armonk, NY, USA). The graphs were constructed in Origin 2021 (OriginLab, Northampton, MA, USA.) and GraphPad Prism Version 8.0 (San Diego, CA, USA). Tukey's $t$-test was used to evaluate the separation of means, and significant differences were detected at a $\mathrm{p}<0.05$.

\section{Results}

\section{Nano-Se improves the biomass and saccharides under $\mathrm{Cd}$} stress

Compared with the control, the addition of Cd significantly decreased the biomass of roots, stems, and leaves at the seedling stage (Fig. 1A-C). The co-application of $\mathrm{Cd}$ and nano-Se significantly improved the biomasses of pepper tissues compared with the $\mathrm{Cd}$ treatment. Cd1Se0.2 and Cd1Se1 enhanced the biomass of roots (38\% and 30\%), stems (33\% and 26\%), and leaves (30\% and $29 \%$ ) compared with the Cd treatment, respectively. However, the biomass of pepper tissues treated with the combination of $\mathrm{Cd}$ and nano-Se was less than those of the control and nano-Se alone.
The change of saccharides in the roots of different treatments with the exception of the control was more obvious than that in the leaves (Fig. 1D-G). The saccharide compounds arabinose, glucose, fructose, and sucrose in the roots notably increased, while the arabinose and fructose levels in the leaves had no obvious difference compared with the control. $\mathrm{Cd}, \mathrm{Cd} 1 \mathrm{Se} 0.2$, and $\mathrm{Cd} 1 \mathrm{Se} 1$ increased the content of arabinose by $48 \%, 55 \%$, and $32 \%$ in the roots, respectively, while there was no significant difference between them. The changing trend of glucose and sucrose was the most obvious since they maintained the upward trend in different tissues compared with the control. The levels of glucose increased by 1.2-, 2.3-, and 2.4-fold compared with the control in the roots following treatment with $\mathrm{Cd}, \mathrm{Cd} 1 \mathrm{Se} 0.2$, and $\mathrm{Cd} 1 \mathrm{Se} 1$, respectively. $\mathrm{Cd} 1 \mathrm{Se} 0.2$ and Cd1Se1 enhanced the content of glucose by $94 \%$ and $101 \%$ in the roots relative to the $\mathrm{Cd}$, respectively. Combinations of $\mathrm{Cd}$ and nano-Se in different proportions increased the levels of glucose in leaves by $95 \%, 115 \%$, and $77 \%$ compared with the control. Cd, Cd1Se0.2, and Cd1Se1 also enhanced the contents of sucrose in the roots by 1.6-, 1.9-, and 1.6-fold, respectively, and by 


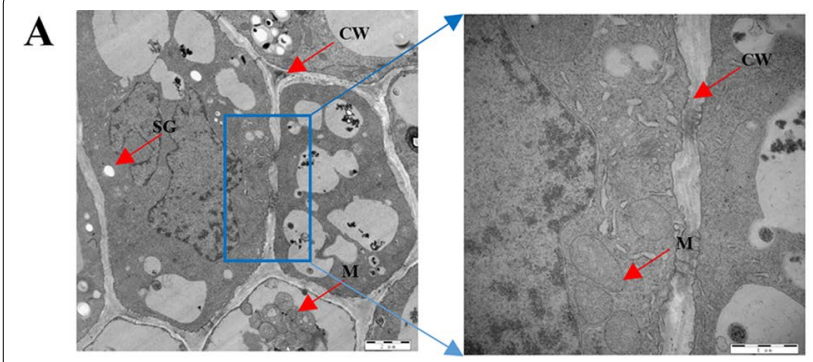

C

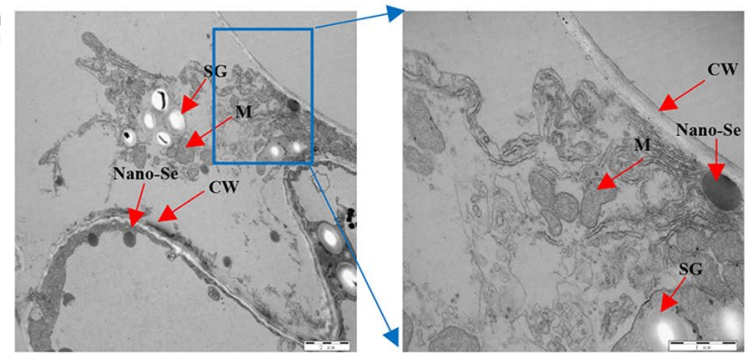

$\mathbf{E}$

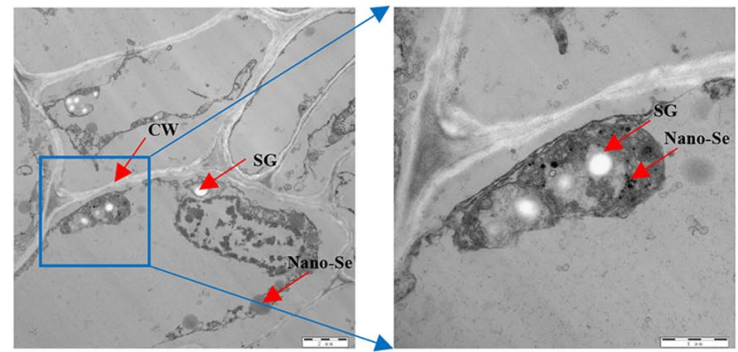

B
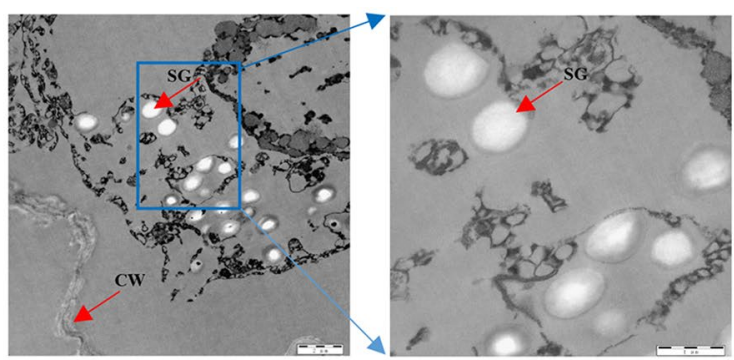

D
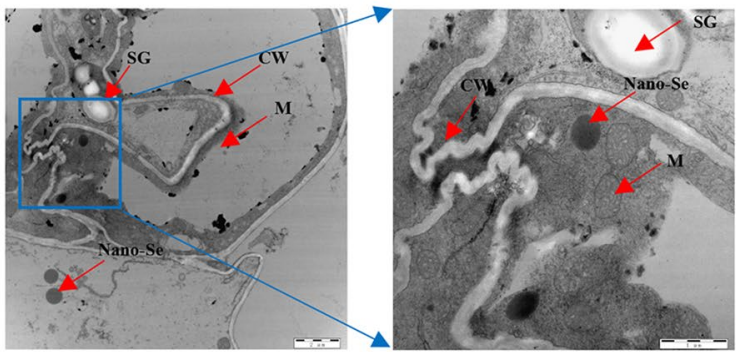

F

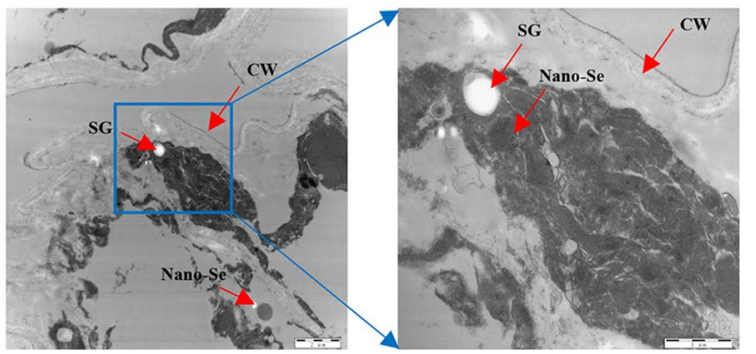

Fig. 2 Effects of the control (A), Cd1 (B), Se0.2 (C), Se1 (D), Cd1Se0.2 (E), and Cd1Se1 (F) on the ultrastructure (CW, M, and SG) of roots by TEM. Cell wall: CW, M: mitochondrion, SG: starch granules. TEM: transmission electron microscopy

$69 \%, 135 \%$, and $110 \%$ in the leaves compared with the control, respectively.

\section{Nano-Se alleviates the ultrastructural damage induced by $\mathrm{Cd}$}

The ultrastructure within the root tip cells of pepper with different treatments is shown in Fig. 2. The root ultrastructure of control, nano-Se0.2, and nano-Se1 had clear mitochondria and cell walls (Fig. 2A, C, and D). The plants treated with nano-Se0.2 and nano-Se1 accumulated more selenium nanoparticles in the cell wall and inside the cell. However, Cd, Cd1Se0.2, and Cd1Se1 resulted in the enlargement of mitochondria and irregular cell walls in root tip cells compared with the control (Fig. 2B, E, and F). Compared with Cd alone, Cd1Se0.2 could restore the morphological damage of mitochondria and cell walls. In addition, the tissues treated with Cd1Se0.2 and Cd1Se1 accumulated fewer starch granules. As the concentration of nano-Se increased, the root tip cells were severely damaged, as manifested by incomplete cell walls and the rupture of mitochondria.

\section{Nano-Se affects the accumulation of $\mathrm{Cd}$ and total Se and the speciation of $\mathrm{Se}$}

$\mathrm{Cd}$ accumulated in the roots, stems, and leaves since the nutrient mixtures contained some $\mathrm{Cd}^{2+}$. As shown in Fig. $3 \mathrm{~A}-\mathrm{C}$, the concentration of $\mathrm{Cd}$ was the highest in roots and was followed by the stems and leaves. The content of $\mathrm{Cd}$ in stems and leaves was much lower than that in the roots. The combination of nano-Se and $\mathrm{Cd}$ (Cd1Se0.2 and Cd1Se1) significantly decreased the levels of $\mathrm{Cd}$ in the roots, stems, and leaves of pepper plants than the $\mathrm{Cd}$ alone. The levels of $\mathrm{Cd}$ in the roots decreased by $17 \%$ and $13 \%$, while those in the stems decreased by $36 \%$ and $30 \%$. The levels in the leaves decreased by $40 \%$ and $42 \%$ in the Cd1Se 0.2 and Cd1Se 1 treatments, respectively, compared with the $\mathrm{Cd}$ treatment.

Different effects of treatments on the concentrations of Se in pepper tissues were examined (Fig. 3D-F). There was no significant difference in the Se content in pepper tissues without Se treatment. Increasing the concentration of nano-Se significantly increased the level of Se. Enzymatic hydrolysis was used to extract the Se species from the pepper tissues, and they were detected using 


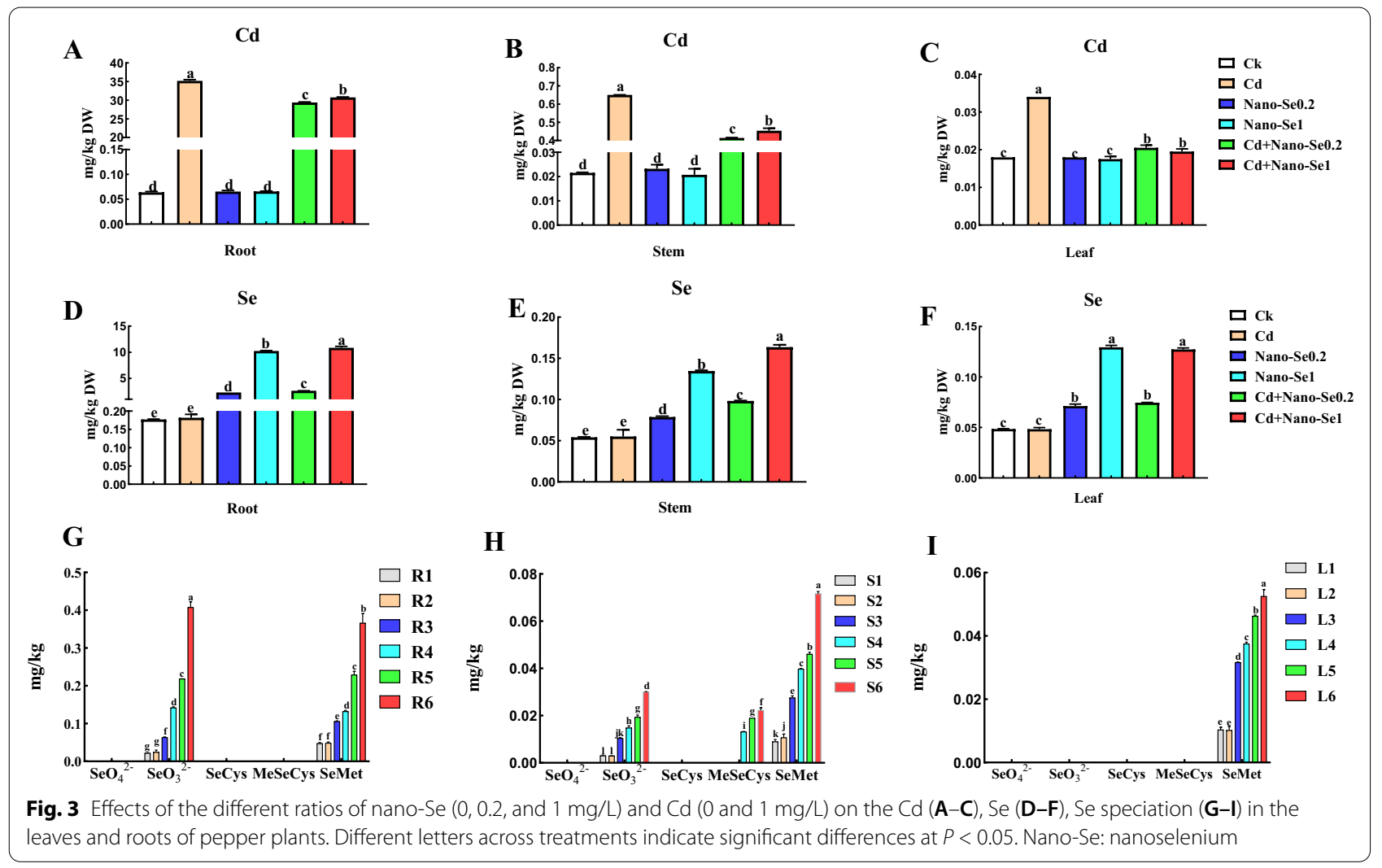

HPLC-ICP-MS (Fig. 3G-I). The Se (IV), Se (VI), SeCys, $\mathrm{MeSeCys}$, and SeMet were identified and quantified in different tissues. As a whole, the order of contents of Se speciation in the roots and aboveground parts of pepper was SeMet $>$ Se (IV) $>$ MeSeCys. SeMet was determined to be the predominant species in all of the pepper tissues. Se (IV) was also identified as the main form of Se in the roots and stems. A small amount of MeSeCys was also measured in the stems that had been treated with Se1, Cd1Se0.2, and Cd1Se1. Compared with the nano$\mathrm{Se} 0.2$ and nano-Se1 treatments, the content of Se (IV) in the roots increased by 2.4 - and 1.9-fold, respectively, and increased by $85 \%$ and $102 \%$ in the stems treated with $\mathrm{Cd} 1 \mathrm{Se} 0.2$ and $\mathrm{Cd} 1 \mathrm{Se} 1$, respectively. In addition, the levels of SeMet in the roots increased by $117 \%$ and $177 \%$, by $67 \%$ and $80 \%$ in the stems and was enhanced by $46 \%$ and $40 \%$ in the leaves owing to the combination of $\mathrm{Cd}$ and nano-Se relative to the nano-Se0.2 and nano-Se1 alone, respectively.

\section{Nano-Se regulates plant hormones and the contents of related genes under $\mathrm{Cd}$ stress}

As shown in Fig. 4A-H, these metabolites and genes were significantly altered in the root and leaves. Compared with the control and nano-Se alone, the contents of JA, $\mathrm{ABA}$, and $\mathrm{BL}$ were remarkably enhanced, while the level of salicylic acid (SA) was apparently not affected by $\mathrm{Cd}, \mathrm{Cd} 1 \mathrm{Se} 0.2$, and $\mathrm{Cd} 1 \mathrm{Se} 1$ in the roots/leaves. Cd1Se0.2 and Cd1Se1 increased the level of ABA (32/29\%) in the root but had no apparent alteration in the leaves compared with the $\mathrm{Cd}$ treatment. Intervention with nano$\mathrm{Se} 0.2$ enhanced the content of JA by $16 \%$ in the root and $22 \%$ in the leaves compared with $\mathrm{Cd}$ alone. $\mathrm{Cd} 1 \mathrm{Se} 0.2$ and Cd1Se 1 enhanced the content of BL by $103 / 48 \%$ in the roots but had no apparent changes in the leaves compared with the $\mathrm{Cd}$.

The levels of expression of BZR1,LOX3, ICS2, and $N C D E 1$ of these genes related to metabolites were determined (Fig. 4E-H). The combination of different proportions of $\mathrm{Cd}$ and nano-Se caused significant changes in their expression in the roots and leaves, including $B Z R 1$, $L O X 3$, and NCDE1. The expression of ICS2 did not significantly change from the various treatments in the root and leaves. Compared with the $\mathrm{Cd}$ treatment, $\mathrm{Cd} 1 \mathrm{Se} 0.2$ enhanced the content of $B Z R 1$ in the root by $48 \%$ the level of NCDE1 1 increased by $35 \%$ in the root and $22 \%$ in the leaves.

\section{Nano-Se enhanced the accumulation of lignin-related metabolites and the levels of genes under $\mathrm{Cd}$ stress}

As shown in Fig. 5A, compared with the control, the combination of different ratios of $\mathrm{Cd}$ and nano-Se 

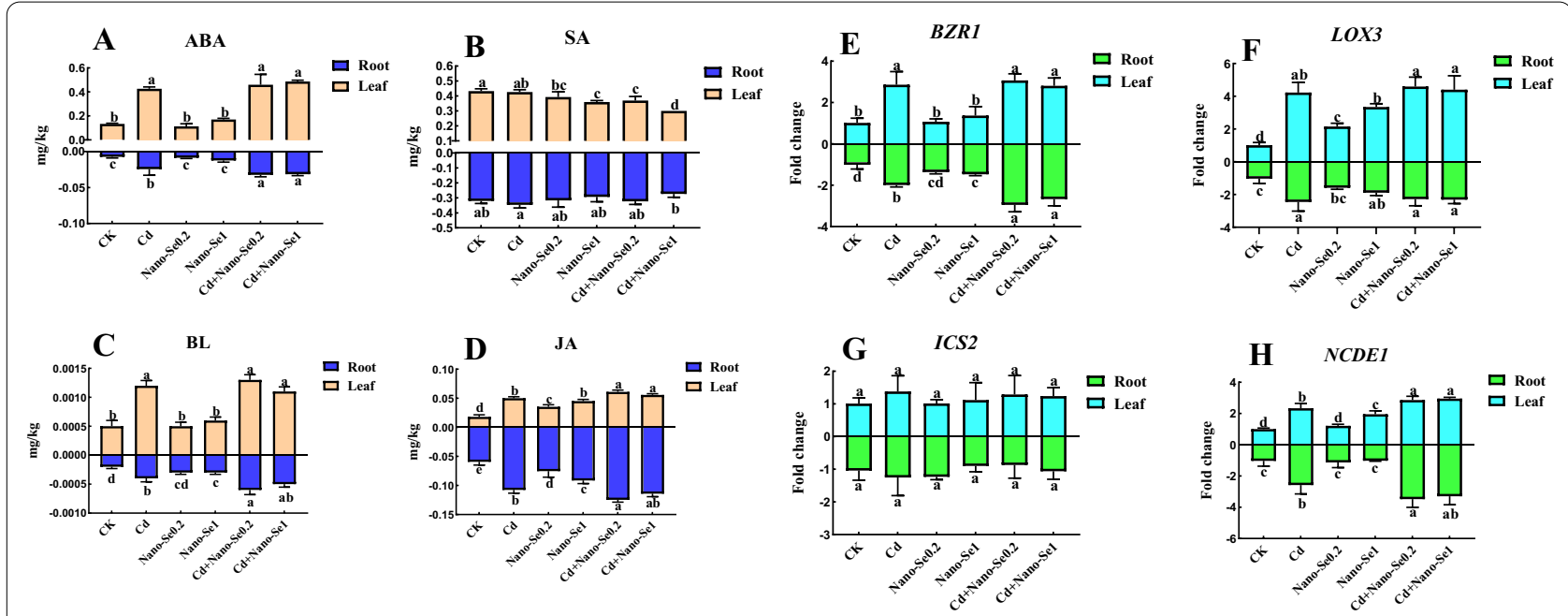

Fig. 4 Effects of different ratios of nano-Se $(0,0.2$, and $1 \mathrm{mg} / \mathrm{L})$ and $\mathrm{Cd}(0$ and $1 \mathrm{mg} / \mathrm{L})$ on the contents of plant metabolites related to hormones: ABA (A), SA (B), BL (C), JA (D), and the level of expression of the genes BZR1(E), LOX3 (F), ICS2 (G), and NCDE1 (H) in leaves and roots of pepper plants. Different letters across treatments indicate significant differences at $P<0.05$
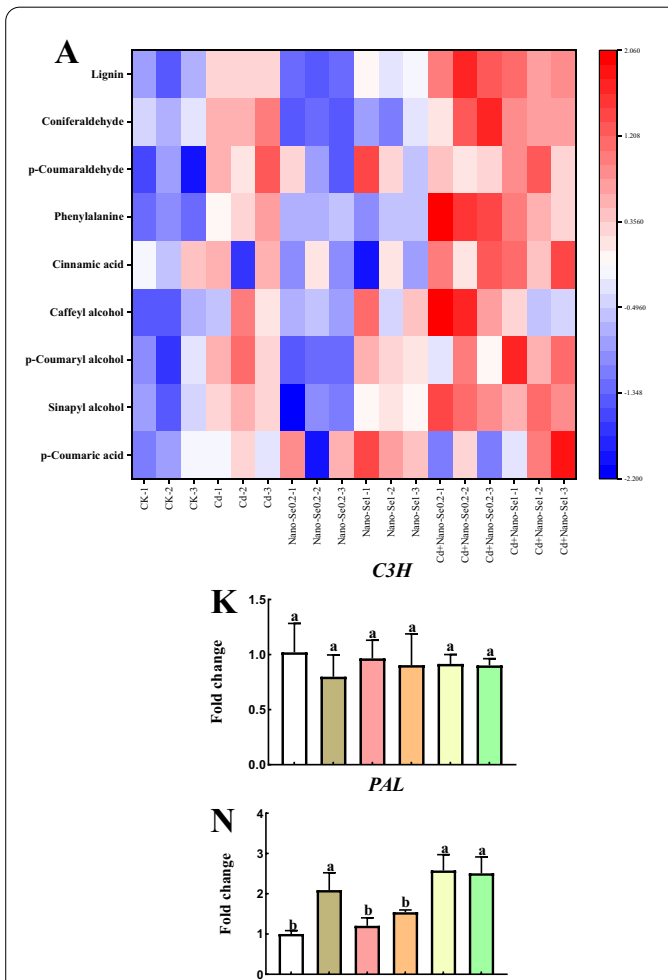

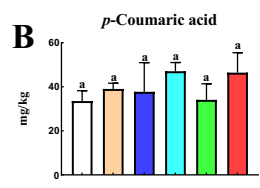

E
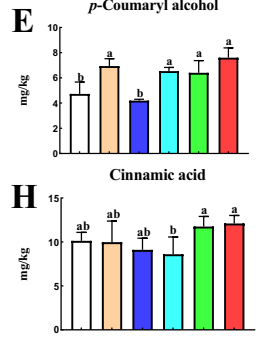

$C A D$
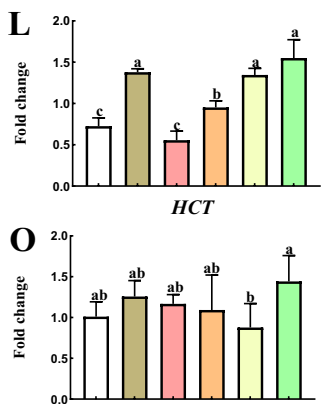
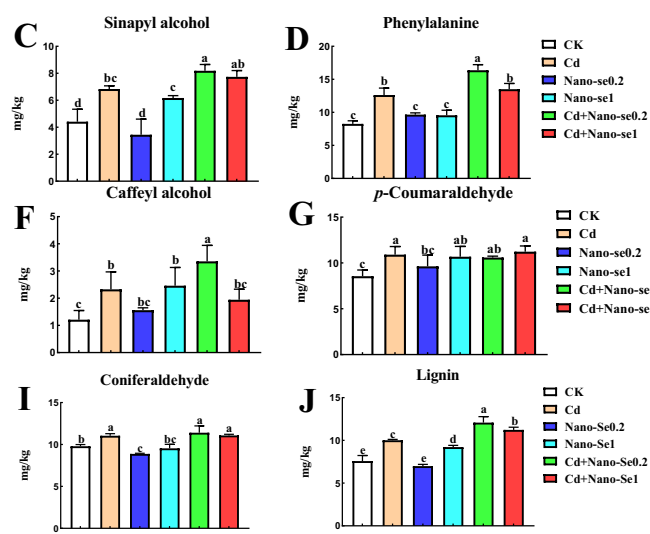

$\mathbf{G}$
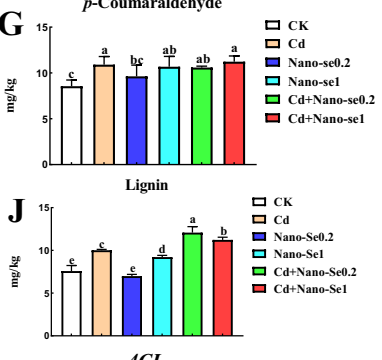

$4 C L$
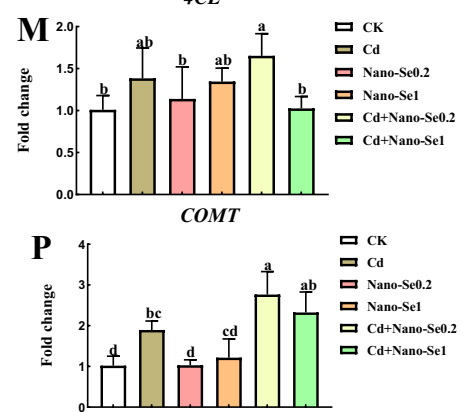

Fig. 5 Effects of different ratios of nano-Se $(0,0.2$, and $1 \mathrm{mg} / \mathrm{L})$ and $\mathrm{Cd}(0$ and $1 \mathrm{mg} / \mathrm{L})$ on the lignin biosynthesis-related metabolites and genes. A heatmap (A) was utilized to analyze the alteration of lignin-related metabolites. Levels of p-coumaric acid (B), sinapyl alcohol (C), phenylalanine (D), p-coumaroyl alcohol (E), caffeoyl alcohol (F), p-coumaraldehyde (G), cinnamic acid (H), coniferaldehyde (I), lignin (J); and the expression of $\mathrm{C} 3 \mathrm{H}(\mathbf{K}), C A D(\mathbf{L}), 4 C L(\mathbf{M}), P A L(\mathbf{N}), H C T(\mathbf{O})$, and COMT (P) were determined in the roots of pepper plants. Different letters across treatments indicate significant differences at $P<0.05$ 

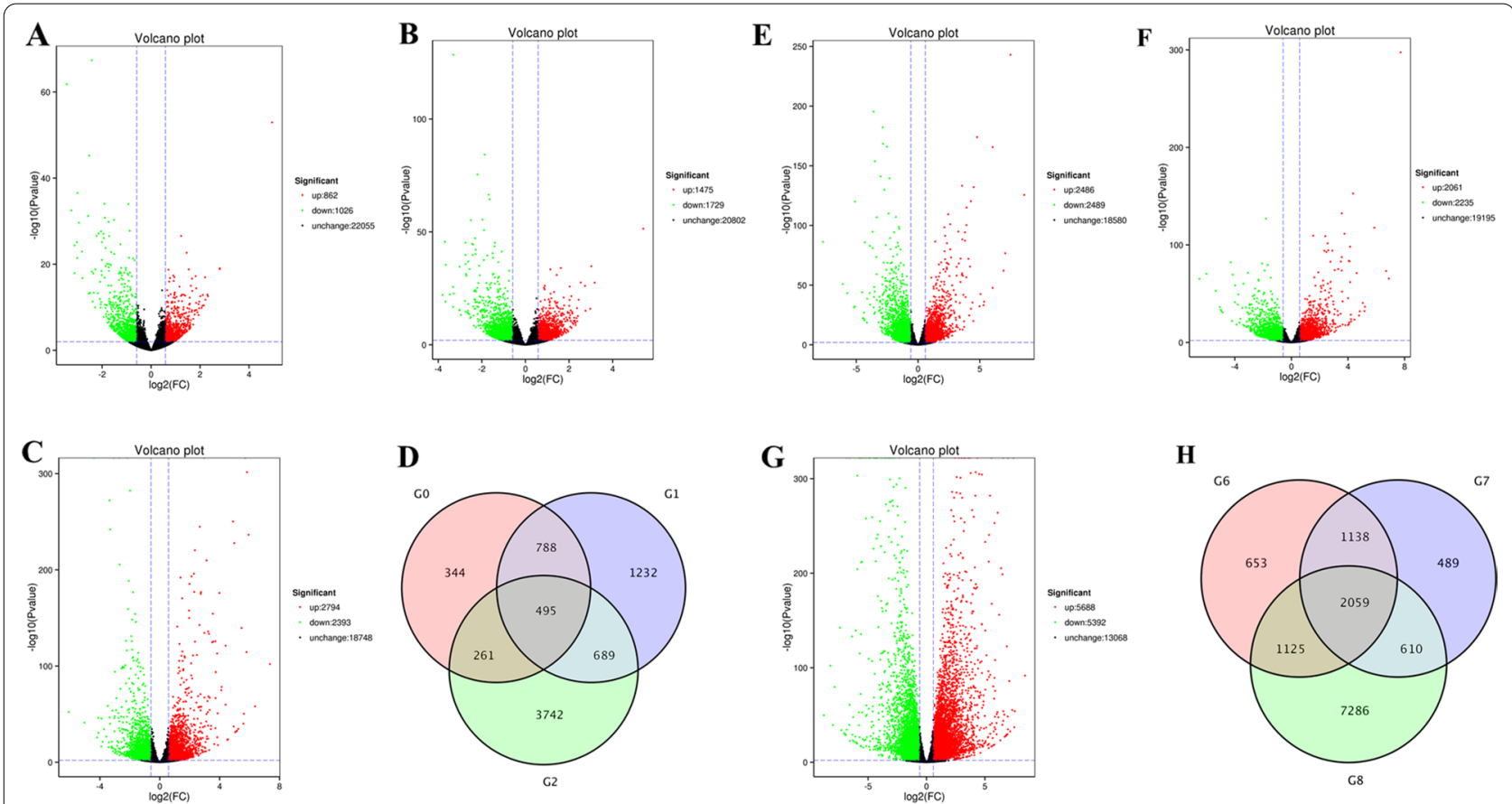

Fig. 6 Volcano plots of differentially expressed genes (DEGs) for pairwise comparison: A, E CK and Cd1; B, F CK and Cd1Se0.2; C, G CK and nan-Se0.2 in the leaves and root. D, H DEGs overlapped in different treatments: CK and Cd (G0/G6); CK and Cd1Se0.2 (G1/G7); CK and nano-Se0.2 $(\mathrm{G} 2 / \mathrm{G} 8)$ in the leaves and roots

regulated the lignin-related metabolites of phenylpropanoid metabolism, including $p$-coumaric acid, sinapyl alcohol, phenylalanine, $p$-coumaryl alcohol, caffeyl alcohol, $p$-coumaraldehyde, cinnamic acid, coniferaldehyde, and lignin. Compared with the Cd treatments, $\mathrm{Cd} 1 \mathrm{Se} 0.2$ enhanced the levels of sinapyl alcohol (20\%), phenylalanine (30\%), and caffeyl alcohol (44\%). The amount of lignin increased by $21 \%$ and $12 \%$ under $\mathrm{Cd} 1 \mathrm{Se} 0.2$ and Cd1Se1 treatments in the root, respectively. However, the levels of $p$-coumaric acid and cinnamic acid had no apparent changes following their treatment.

The levels of expression of the lignin-related genes $C 3 H, C A D, 4 C L, P A L, H C T$, and COMT were measured (Fig. 5K-P). The treatments with $\mathrm{Cd}, \mathrm{Cd} 1 \mathrm{Se} 0.2$, and $\mathrm{Cd} 1 \mathrm{Se} 1$ enhanced their levels of expression in the roots, including $C A D, P A L$, and COMT. $C 3 H, 4 C L$, and $H C T$, had no distinct alterations following treatment with $\mathrm{Cd}$ alone or a combination of $\mathrm{Cd}$ and nano-Se in the root. Compared with the $\mathrm{Cd}$ treatment, $\mathrm{Cd} 1 \mathrm{Se} 0.2$ enhanced the expression of COMT by $46 \%$ in the roots.

\section{Nano-Se resulted in significant changes} in the transcriptome of pepper root and leaves

Four groups of pepper plants with different tissues (root and leaves) were analyzed to identify the transcriptional responses by treatment with nano-Se under $\mathrm{Cd}$ stress (Fig. 6). In the control and Cd treatment (G0 and G6), a total of 1888 DEGs were identified in the G0 groups; 862 were upregulated, and 1026 were downregulated relative to the control in leaves. A total of 4975 DEGs were identified in the G6 groups. A total of 2486 were upregulated, and 2489 were downregulated relative to the control in roots. In the control and $\mathrm{Cd} 1 \mathrm{Se} 0.2$ treatments (G1 and G7), a total of 3204 DEGs were identified in the G1 groups, with 1475 upregulated and 1729 downregulated in the leaves. A total of 4,296 DEGs was identified in the G7 groups with 2061 upregulated and 2235 downregulated in the roots. A total of 5187 DEGs (up 2794 and down 2393) were identified in the control and nano-Se0.2 treatment (G2) in the leaves. A total of 11,080 DEGs (up 5688 and; down 5392) were identified in the control and nano-Se0.2 treatment (G8) in the roots. The DEGs of different treatments are shown in Additional file 1: Table S4.

The GO and KEGG enrichment analysis was used to better understand the transcripts of pepper plants under Cd stress (Fig. 7). The DEGs were primarily classified into molecular functions, biological processes, and cell composition (Additional file 1: Figure S1 and S2). These DEGs in the leaves and roots of different treatments (CK vs. Cd, CK vs. Se0.2, and CK vs. Cd1Se0.2) indicated a significant enrichment in plant hormone signal transduction (Fig. 7A-C) by a KEGG-enriched analysis, while the phenylpropanoid biosynthesis was only markedly enriched in the roots (Fig. 7D-F). 


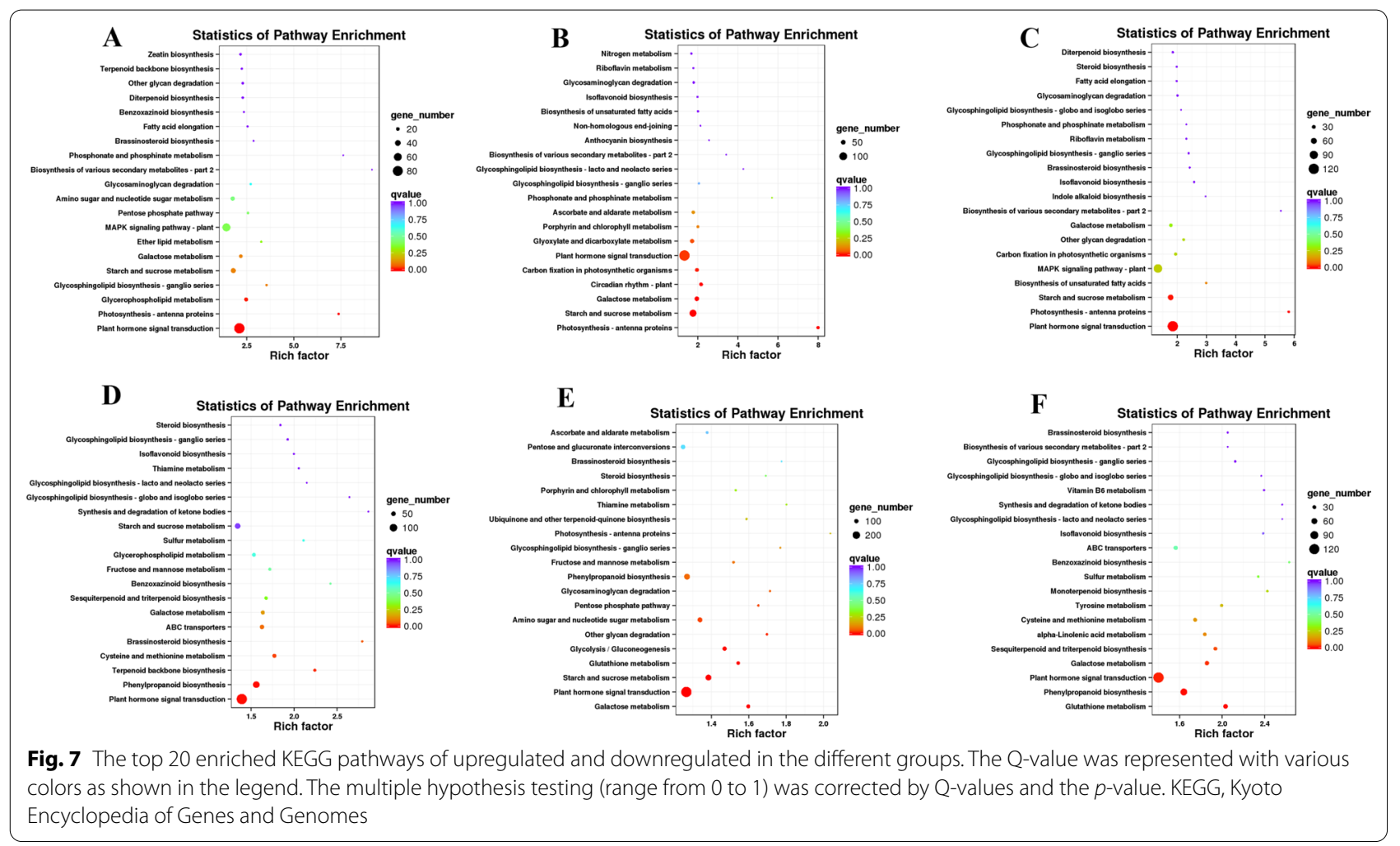

\section{Discussion}

$\mathrm{Cd}$ stress can hinder the growth of plants and cause a disorder of plant metabolism, thus, affecting the yield of crops. The minimization of $\mathrm{Cd}$ absorption in pepper plants is crucial to reduce the exposure to $\mathrm{Cd}$ toxicity and ensure food safety. The application of Se ameliorates the adverse effects of abiotic and biotic stress by adjusting different mechanisms, including the antioxidant system and secondary metabolism. However, few studies have been conducted on the effects of application of nano-Se on the mechanisms of resistance of pepper plants to heavy metal stress. In this study, the specific issues of nano-Seinduced plant growth and the associated absorption and transformation under $\mathrm{Cd}$ stress were examined. Nano-Se also stimulated the integrity of cell wall structure by regulating the lignin biosynthetic pathway in the root. It also improved the resistance by adjusting the signal transduction of plant hormones. These observations demonstrate that nano-Se enhances the tolerance of pepper plants to $\mathrm{Cd}$ stress that is compactly associated with the synergetic regulation of $\mathrm{Se} / \mathrm{Cd}$ uptake and transformation, cellular homeostasis, and plant hormone/lignin-related signal pathway in pepper plants (Fig. 8).

The mass of roots, stems, and leaves of pepper plants decreased significantly under $\mathrm{Cd}$ stress (Fig. $1 \mathrm{~A}-\mathrm{C}$ ). The accumulation of biomass decreased when the plants were subjected to an excessive accumulation of $\mathrm{Cd}$. This could possibly be owing to interference with the uptake of carbohydrate compounds. In this study, it was observed that $\mathrm{Cd}$ in the pepper roots and leaves increased the levels of arabinose, sucrose, glucose, and fructose compared with the control and nano-Se treatments. However, a combination of $\mathrm{Cd}$ and $\mathrm{Se}(\mathrm{Cd} 1 \mathrm{Se} 0.2$ and Cd1Se1) can remarkably enhance the contents of glucose and sucrose compared with the treatment of $\mathrm{Cd}$ alone in the roots and leaves. Shahid et al. found that sodium selenate decreased the $\mathrm{Cd}$ and As levels in the plant, which helped to accumulate sugars and alleviate oxidative stress, thus, enhancing the nitrogen and carbon metabolism triggered by As and/or Cd stress [23]. The study of transcriptomics indicated that the starch and sucrose metabolism changed significantly in the leaves subjected to different treatments $(\mathrm{G} 0, \mathrm{G} 1$, and $\mathrm{G} 2)$ but not in the roots $(\mathrm{G6}, \mathrm{G7}$, and G8). The accumulation of soluble sugar in leaves can help the plants to maintain water status and eliminate ROS under abiotic stress [24].

Selenium has been used as a base fertilizer or as a foliar spray to improve the content of Se in the edible parts of crops. The absorption of Se and its translocation and distribution in plants depends on the species of plant, mode of usage and concentration, physiological conditions, membrane transporter activity, and translocation mechanism [25]. In this study, the content of Se increased significantly with the increase in concentration of nano-Se. 


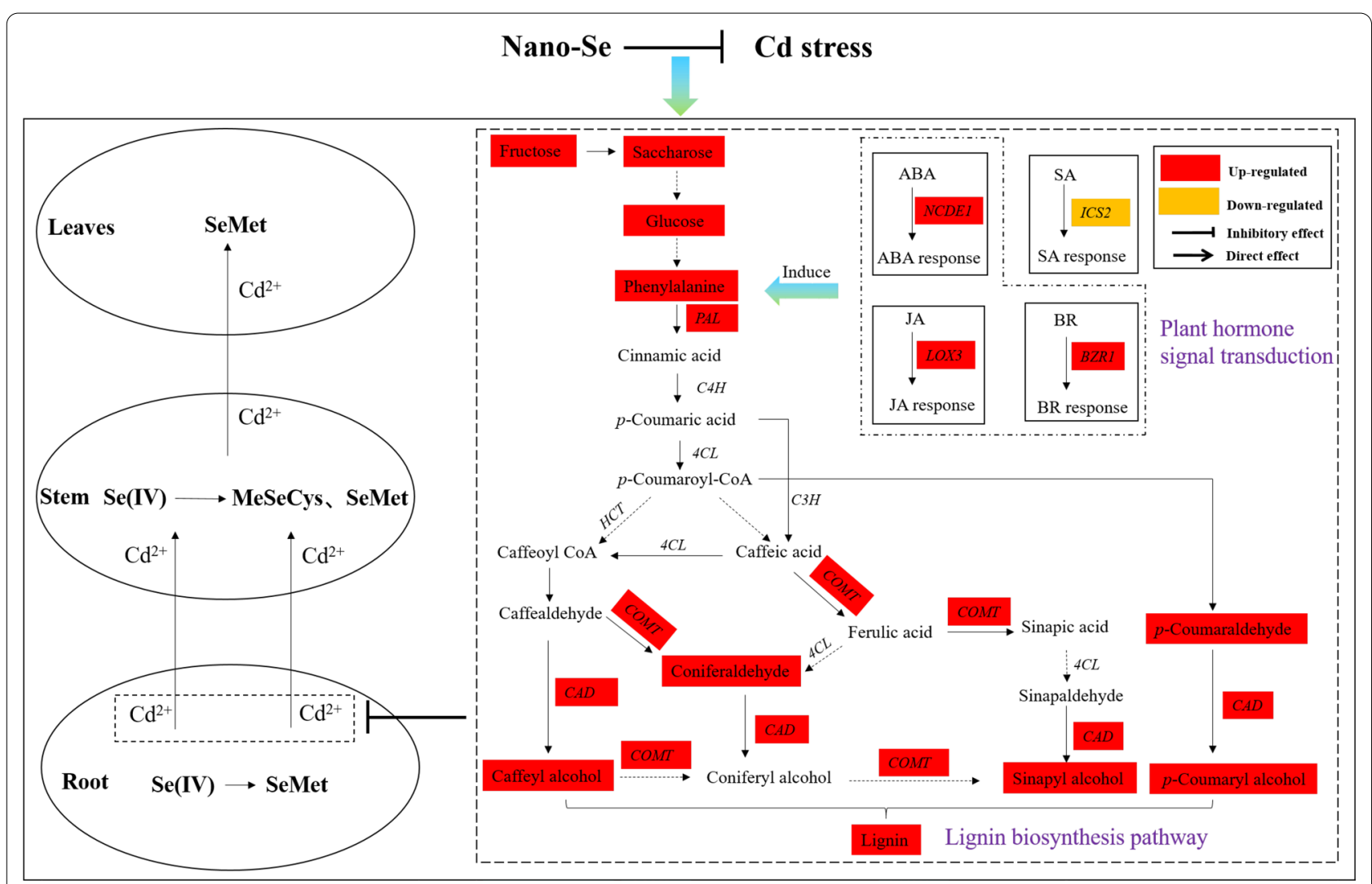

Fig. 8 The proposed protective mechanism of nano-Se enhancing the resistance of pepper plants under Cd stress

Most of the Se compounds transformed by nano-Se biofortification are selenoamino acids, primarily in the form of SeMet and MeSeCys. Several studies reported that the application of Se can reduce the absorption and transformation of plants and mitigate metabolic disturbances induced by heavy metals. Nano-Se inhibited the accumulation of $\mathrm{Cd}$ in the roots, and the amounts of $\mathrm{Cd}$ were significantly reduced in the upper parts of pepper. In addition, the content of $\mathrm{Cd}$ in the roots was greater than that in the stems and leaves (Fig. 2A-C). The possible mechanism could be to reduce the accumulation of $\mathrm{Cd}$ in plants tissues by binding $\mathrm{Cd}$ and converting it into other non-absorbable forms. This experiment also indicated that nano-Se absorbed by the roots can be quickly transformed into an organic state (SeMet) in the roots. Selenocompounds could form a complex with $\mathrm{Cd}$, which could effectively retain $\mathrm{Cd}$ and inhibit its upward translocation. This phenomenon is also reflected in other crops, including rice (Oryza sativa L) [26, 27] and bok choy (Brassica chinensis) [28].

Few studies have examined the influence of nano-Se on the metabolites and genes related to lignin synthesis in the phenylpropanoid pathway of pepper plants. Previous research showed that the $P A L, C 3 H, C A D, 4 C L$,
$H C T$, and COMT genes encode compounds in the phenylpropanoid pathway that can lead to lignin biosynthesis in plants. The levels of these genes positively correlate with the lignin levels of pepper plants. Lignin biosynthesis supports plant growth and the transportation of water and nutrients. As shown in Fig. 5, the contents of $P A L$, $C A D, 4 C L$, and $C O M T$ increased significantly following treatment with the combination of different proportions of $\mathrm{Cd}$ and nano-Se. Cd1Se0.2 was the most effective. Studies have found that the level of $P A L$ was upregulated during lignin biosynthesis in tobacco [29]. The lignin biosynthetic gene of $4 C L$ is activated by MYB transcription factors, which induce lignin synthesis. The levels of $\mathrm{C} 3 \mathrm{H}$, $C A D, H C T, 4 C L$, and $C O M T$ were upregulated in lignin biosynthesis, which resulted in the accumulation of lignin and thickened cell walls, thus, enhancing osmotic protective agents and mitigating the effects of salt in apple [30]. The formation of $p$-coumaryl alcohol, caffeyl alcohol, and coniferyl alcohol is catalyzed by cinnamyl alcohol dehydrogenase in the biosynthesis of monolignol [31]. Since plants are continually developing in response to a changing environment, fixation by plants reprograms the distribution of metabolites to maintain vigorous growth and survival [32]. Nano-Se biofortification also significantly 
alleviated the damage induced by $\mathrm{Cd}$ owing to improvements in the ultrastructural integrity of the plasma membrane and mitochondria in the root tip, which improved the growth of pepper plants (Fig. 2). Zhao et al. suggested that Se improved the morphology of roots and regulated the absorption of nutrients by the roots. This could play a comprehensive role in reducing the absorption of $\mathrm{Cr}$ by roots, thus, reducing $\mathrm{Cr}$ stress and maintaining plant growth [33]. In our study, different ratios of $\mathrm{Cd}$ and nanoSe (Cd1Se0.2 and Cd1Se1) were more effective than $\mathrm{Cd} / \mathrm{Se}$ alone in enhancing the levels of sinapyl alcohol, phenylalanine, $p$-coumaroyl alcohol, caffeoyl alcohol, and coniferaldehyde in the pepper root, which result in the induction of lignin biosynthesis (Fig. 5A-J). These metabolites that were upregulated in the lignin biosynthetic pathway are regarded as a determinant of lignin characteristics, which are conducive to the engineering of lignin to improve the development and utilization of plants [34]. Cui et al. indicated that Se reduced the level of ROS and enhanced the lignin content and thickness of the cell walls under $\mathrm{Cd}$ stress, resulting in an enhancement of the mechanical force of the cell walls by inducing the expression of lignin synthesis and Cd-related genes [35]. Therefore, we conclude that the application of nanoSe induced the biosynthesis of lignin-related genes and metabolites, thereby enhancing the mechanical strength of the cell wall and inhibiting the cellular absorption of Cd.

Importantly, the addition of nano-Se can regulate signal transduction by plant hormones and coordinately affect the lignin metabolic pathway under Cd stress. Plant hormones play an important role in coordinating responses to environmental change and are essential for stress tolerance and the yield of crops [9]. The root morphology and metal transporters were changed by adjusting the plant hormones and allocating the nutrient components [36]. Foliar spray plant hormones, such as JA, SA, and $\mathrm{BR}$, improve the resistance, attributes of quality, nutrients, and shelf life in different crops [37, 38]. In our study, Cd1Se0.2 can significantly increase the expression of genes related to plant hormones in the roots and leaves compared with those of other treatments, including BZR1, LOX3, and NCDE1. These genes also upregulated the plant hormones $\mathrm{BR}, \mathrm{ABA}$, and JA in the root and leaves under $\mathrm{Cd}$ stress. In our previous study, nanoSe significantly increased the contents of genes related to JA and ABA in pepper fruit [22]. Low MeJA concentrations can mitigate the adverse effect of $\mathrm{Cd}$ by significantly increasing the level of JA observed at $48 \mathrm{~h}$ under $50 \mathrm{mg} / \mathrm{L} \mathrm{Cd}$ and $50 \mathrm{mg} / \mathrm{L} \mathrm{Cd}+0.1 \mathrm{mmol} / \mathrm{L}$ MeJA treatment in the Capsicum frutescens var. fasciculatum seedlings [12]. JAs enhance the defense of the crop against water loss by producing more osmotic compounds, such as cuticles, proline, lignin, waxes, and polyphenols [39]. JAs play an important role in the induction of gene expression and the increase in PAL activity, which is the primary enzyme in the pathway that produces phenolic compounds [39]. The mechanism of BRs mitigates heavy metal toxicity by boosting the antioxidant system and expression of MAPK and increasing the levels of proline, antioxidants, potassium, sodium ions, and osmolytes [40, 41]. ABA mitigated the adverse effects of $\mathrm{Cu}$ stress and protected the glandular trichomes, which improved the development and oxidative stress tolerance of plants by adjusting antioxidant defenses [42]. They synergistically regulate plant metabolism and enhance stress resistance through the interaction of SA, JA, and ABA [43]. In addition, diverse phytohormone signal pathways, such as JA, can also regulate phenylpropanoid metabolism [32].

\section{Conclusions}

The diagram illustrates the potential of nano-Se in reducing the toxicity of $\mathrm{Cd}$ in pepper plants (Fig. 8). In this study, treatment with $\mathrm{Cd}$ alone observably inhibited growth, the accumulation of biomass, and absorption of nutrients. It also severely impaired the cellular wall integrity and the structure of mitochondria. Nano-Se biofortification markedly ameliorates the damage induced by $\mathrm{Cd}$ by reducing its content and increasing the accumulation of biomass in the form of glucose and sucrose in the roots and leaves. The Se compounds transformed by nano-Se were primarily in the form of SeMet and MeSeCys. The key differential metabolites of plant signal transduction and phenylpropanoid metabolism were screened by utilizing transcriptomics and determining the target metabolites. The levels of expression of lignin-related genes (PAL, CAD, $4 C L$, and COMT) and the contents of metabolites (sinapyl alcohol, phenylalanine, $p$-coumaryl alcohol, caffeyl alcohol, and coniferaldehyde) in the roots were observably increased by treatment with $\mathrm{Cd} 1 \mathrm{Se} 0.2$, resulting in an enhancement of thickness of the cell walls. It also improved the stress-responsive resistance by inducing the genes involved in plant signal transduction (BZR1, LOX3, and NCDE1) and the metabolites (BR, $\mathrm{ABA}$, and JA) in the root and leaves. Overall, this study provides an enhanced understanding of the protective effect of Se in managing abiotic stress and improving the ability of plants to resist environmental stress.

\section{Supplementary Information}

The online version contains supplementary material available at https://doi. org/10.1186/s12951-021-01061-6.

Additional file 1: Table S1. UPLC-MS/MS parameters of plant hormones; Figure S1. GO class of different treatments in the root; Table S2. 
UPLC-MS/MS parameters of lignin-related metabolites; Figure S2. GO class of different treatments in the leaves; Table S3. Primer sequences for qPCR; Table S4. Statistics of the number of differentially expressed genes.

\section{Acknowledgements}

This work was supported by a grant from the National Natural Science Foundation of China (3217170041).

\section{Authors' contributions}

DL: Methodology, investigation, data curation, formal analysis, visualization, writing —original draft. CZ: Investigation, data curation, formal analysis. JM and KD: Conceptualization, methodology. YW: Conceptualization, methodology. JZ and LK: Investigation, data curation. QA: Writing - review \& editing. J-QL: Conceptualization. CP: Supervision. All authors read and approved the final manuscript.

\section{Availability of data and materials}

All data generated or analyzed during this study are included in this published article within each editable graph.

\section{Declarations}

\section{Ethics approval and consent to participate}

Not applicable.

\section{Consent for publication \\ Not applicable.}

\section{Competing interests}

The authors declare that they have no known competing financial interests or personal relationships that could have appeared to influence the work reported in this paper.

\section{Author details}

'Innovation Center of Pesticide Research, Department of Applied Chemistry, College of Science, China Agricultural University, Beijing 100193, China. ${ }^{2}$ Institute of Food Science and Technology, Chinese Academy of Agricultural Sciences, Beijing 100193, China.

Received: 18 August 2021 Accepted: 25 September 2021

Published online: 12 October 2021

\section{References}

1. Berni R, Luyckx M, Xu X, Legay S, Sergeant K, Hausman J-F, Lutts S, Cai G, Guerriero G. Reactive oxygen species and heavy metal stress in plants: Impact on the cell wall and secondary metabolism. Environ Exp Bot 2019;161:98-106. https://doi.org/10.1016/j.envexpbot.2018.10.017.

2. Zhang H, Yuan X, Xiong T, Wang H, Jiang L. Bioremediation of cocontaminated soil with heavy metals and pesticides: Influence factors, mechanisms and evaluation methods. Chem Eng J. 2020;398:125657. https://doi.org/10.1016/j.cej.2020.125657.

3. He SY, He ZL, Yang XE, Stoffella PJ, Baligar VC. Soil biogeochemistry, plant physiology, and phytoremediation of cadmium-contaminated aoils. Adv Agron. 2015;134:135-225. https://doi.org/10.1016/bs.agron.2015.06.005.

4. Javed MT, Akram MS, Tanwir K, Chaudhary HJ, Ali Q, Stoltz E, Lindberg S. Cadmium spiked soil modulates root organic acids exudation and ionic contents of two differentially Cd tolerant maize (Zea mays L.) cultivars. Ecotoxicol Environ Saf. 2017;141:216-25. https://doi.org/10.1016/j.ecoenv. 2017.03.027.

5. Sobrino-Plata J, Meyssen D, Cuypers A, Escobar C, Hernandez LE. Glutathione is a key antioxidant metabolite to cope with mercury and cadmium stress. Plant Soil. 2014;377(1-2):369-81. https://doi.org/10. 1007/s11104-013-2006-4.

6. Sanatombi K, Rajkumari S. Effect of processing on quality of pepper: a review. Food Rev Int. 2020;36(6):626-43. https://doi.org/10.1080/87559 129.2019.1669161.
7. Cho SC, Lee H, Choi BY. An updated review on molecular mechanisms underlying the anticancer effects of capsaicin. Food Sci Biotechnol. 2017;26(1):1-13. https://doi.org/10.1007/s10068-017-0001-x.

8. Chen Y, Hu W, Huang B, Weindorf DC, Rajan N, Liu X, Niedermann S. Accumulation and health risk of heavy metals in vegetables from harmless and organic vegetable production systems of China. Ecotoxicol Environ Saf. 2013:98:324-30. https://doi.org/10.1016/j.ecoenv.2013.09.037.

9. Haider FU, Liqun C, Coulter JA, Cheema SA, Wu J, Zhang R, Wenjun M, Faroog M. Cadmium toxicity in plants: impacts and remediation strategies. Ecotoxicol Environ Saf. 2021;211:111887. https://doi.org/10.1016/j. ecoenv.2020.111887.

10. Adrees M, Khan ZS, Ali S, Hafeez M, Khalid S, Ur Rehman MZ, Hussain A, Hussain K, Shahid Chatha SA, Rizwan M. Simultaneous mitigation of cadmium and drought stress in wheat by soil application of iron nanoparticles. Chemosphere. 2020;238:124681. https://doi.org/10.1016/j.chemo sphere.2019.124681.

11. Xu D, Zhao Y, Zhou H, Gao B. Effects of biochar amendment on relieving cadmium stress and reducing cadmium accumulation in pepper. Environ Sci Pollut Res. 2016;23(12):12323-31. https://doi.org/10.1007/ s11356-016-6264-6.

12. Yan ZZ, Chen J, Li XZ. Methyl jasmonate as modulator of Cd toxicity in Capsicum frutescens var. fasciculatum seedlings. Ecotoxicol Environ Saf. 2013;98:203-9. https://doi.org/10.1016/j.ecoenv.2013.08.019.

13. Guo B, Liu C, Ding NF, Fu QL, Lin YC, Li H, Li NY. Silicon alleviates cadmium toxicity in two cypress varieties by strengthening the exodermis tissues and stimulating phenolic exudation of roots. J Plant Growth Regul, 2016:35(2):420-9. https://doi.org/10.1007/s00344-015-9549-y.

14. Wang M, Chen L, Chen SB, Ma YB. Alleviation of cadmium-induced root growth inhibition in crop seedlings by nanoparticles. Ecotoxicol Environ Saf. 2012;79:48-54. https://doi.org/10.1016/j.ecoenv.2011.11.044.

15. Zhao Y, Hu C, Wu Z, Liu X, Cai M, Jia W, Zhao X. Selenium reduces cadmium accumulation in seed by increasing cadmium retention in root of oilseed rape (Brassica napus L.). Environ Exp Bot. 2019;158:161-70. https:// doi.org/10.1016/j.envexpbot.2018.11.017.

16. Liu N, Jiang Z, Li X, Liu H, Li N, Wei S. Mitigation of rice cadmium (Cd) accumulation by joint application of organic amendments and selenium (Se) in high-Cd-contaminated soils. Chemosphere. 2020;241:125106. https://doi.org/10.1016/j.chemosphere.2019.125106.

17. Ulhassan Z, Gill RA, Huang H, Ali S, Mwamba TM, Ali B, Huang Q, Hamid Y, Khan AR, Wang J, Zhou W. Selenium mitigates the chromium toxicity in Brassicca napus L. by ameliorating nutrients uptake, amino acids metabolism and antioxidant defense system. Plant Physiol Biochem. 2019;145:142-52. https://doi.org/10.1016/j.plaphy.2019.10.035.

18. El-Ramady HR, Domokos-Szabolcsy É, Abdalla NA, Alshaal TA, Shalaby TA, Sztrik A, Prokisch J, Fári M. Selenium and nano-selenium in agroecosystems. Environ Chem Lett. 2014;12(4):495-510. https://doi.org/10.1007/ s10311-014-0476-0.

19. Ismael MA, Elyamine AM, Moussa MG, Cai M, Zhao X, Hu C. Cadmium in plants: uptake, toxicity, and its interactions with selenium fertilizers. Metallomics. 2019;11(2):255-77. https://doi.org/10.1039/c8mt00247a.

20. D.I.A. DR, Hoagland. The water-culture method for growing plants without soil. Calif Agric Exp Stn Circ. 1950;347:1-32.

21. Li D, An Q, Wu Y, Li J-Q, Pan C. Foliar application of selenium nanoparticles on celery stimulates several nutrient component levels by regulating the a-linolenic acid pathway. ACS Sustain Chem Eng. 2020;8(28):10502-10. https://doi.org/10.1021/acssuschemeng.0c02819.

22. Li D, Zhou C, Zhang J, An Q, Wu Y, Li JQ, Pan C. Nanoselenium foliar applications enhance the nutrient quality of pepper by activating the capsaicinoid synthetic pathway. J Agric Food Chem. 2020;68(37):9888-95. https://doi.org/10.1021/acs.jafc.0c03044.

23. Shahid MA, Balal RM, Khan N, Zotarelli L, Liu GD, Sarkhosh A, FernándezZapata JC, Martínez Nicolás JJ, Garcia-Sanchez F. Selenium impedes cadmium and arsenic toxicity in potato by modulating carbohydrate and nitrogen metabolism. Ecotoxicol Environ Saf. 2019;180:588-99. https:// doi.org/10.1016/j.ecoenv.2019.05.037.

24. Sevcikova H, Maskova P, Tarkowska D, Masek T, Lipavska H. Carbohydrates and gibberellins relationship in potato tuberization. J Plant Physiol. 2017;214:53-63. https://doi.org/10.1016/j.jplph.2017.04.003.

25. Gupta M, Gupta S. An overview of selenium uptake, metabolism, and toxicity in plants. Front Plant Sci. 2016;7:2074. https://doi.org/10.3389/ fpls.2016.02074. 
26. Guo Y, Mao K, Cao H, Ali W, Lei D, Teng D, Chang C, Yang X, Yang Q, Niazi NK, Feng $X$, Zhang $H$. Exogenous selenium (cadmium) inhibits the absorption and transportation of cadmium (selenium) in rice. Environ Pollut. 2021;268(Pt A):115829. https://doi.org/10.1016/j.envpol.2020. 115829 .

27. Hussain B, Lin Q, Hamid Y, Sanaullah M, Di L, Hashmi M, Khan MB, He $Z$, Yang X. Foliage application of selenium and silicon nanoparticles alleviates $\mathrm{Cd}$ and Pb toxicity in rice (Oryza sativa L.). Sci Total Environ. 2020;712:136497. https://doi.org/10.1016/.scitotenv.2020.136497.

28. Yu Y, Zhuang Z, Luo LY, Wang YQ, Li HF. Difference between selenite and selenate in selenium transformation and the regulation of cadmium accumulation in Brassica chinensis. Environ Sci Pollut Res Int. 2019:26(24):24532-41. https://doi.org/10.1007/s11356-019-05705-x.

29. Silva FLB, Vieira LGE, Ribas AF, Moro AL, Neris DM, Pacheco AC. Proline accumulation induces the production of total phenolics in transgenic tobacco plants under water deficit without increasing the G6PDH activity. Theor Exp Plant Physiol. 2018;30(3):251-60. https://doi.org/10.1007/ s40626-018-0119-0.

30. Chen K, Song M, Guo Y, Liu L, Xue H, Dai H, Zhang Z. MdMYB46 could enhance salt and osmotic stress tolerance in apple by directly activating stress-responsive signals. Plant Biotechnol J. 2019;17(12):2341-55. https:// doi.org/10.1111/pbi.13151.

31. Barros J, Escamilla-Trevino L, Song L, Rao X, Serrani-Yarce JC, Palacios MD, Engle N, Choudhury FK, Tschaplinski TJ, Venables BJ, Mittler R, Dixon RA. 4-Coumarate 3-hydroxylase in the lignin biosynthesis pathway is a cytosolic ascorbate peroxidase. Nat Commun. 2019. https://doi.org/10. 1038/s41467-019-10082-7.

32. Dong NQ, Lin HX. Contribution of phenylpropanoid metabolism to plant development and plant-environment interactions. J Integr Plant Biol. 2021;63(1):180-209. https://doi.org/10.1111/jipb.13054.

33. Zhao Y, Hu C, Wang X, Qing X, Wang P, Zhang Y, Zhang X, Zhao X. Selenium alleviated chromium stress in Chinese cabbage (Brassica campestris L. ssp. Pekinensis) by regulating root morphology and metal element uptake. Ecotoxicol Environ Saf. 2019;173:314-21. https://doi.org/10. 1016/j.ecoenv.2019.01.090.

34. Wang JP, Matthews ML, Naik PP, Williams CM, Ducoste JJ, Sederoff RR, Chiang VL. Flux modeling for monolignol biosynthesis. Curr Opin Biotechnol. 2019;56:187-92. https://doi.org/10.1016/j.copbio.2018.12.003.

35. Cui J, Liu T, Li Y, Li F. Selenium reduces cadmium uptake into rice suspension cells by regulating the expression of lignin synthesis and cadmium-related genes. Sci Total Environ. 2018;644:602-10. https://doi. org/10.1016/j.scitotenv.2018.07.002.

36. Betti C, Della Rovere F, Piacentini D, Fattorini L, Falasca G, Altamura MM. Jasmonates, ethylene and brassinosteroids control adventitious and lateral rooting as stress avoidance responses to heavy metals and metalloids. Biomolecules. 2021. https://doi.org/10.3390/biom11010077.

37. Bürger M, Chory J. Stressed out about hormones: how plants orchestrate immunity. Cell Host Microbe. 2019;26(2):163-72. https://doi.org/10. 1016/j.chom.2019.07.006.

38. Garcia-Garcia AL, Garcia-Machado FJ, Borges AA, Morales-Sierra S, Boto A, Jimenez-Arias D. Pure organic active compounds against abiotic stress: a biostimulant overview. Front Plant Sci. 2020;11:575829. https://doi.org/ 10.3389/fpls.2020.575829.

39. Wasternack C, Hause B. Jasmonates: biosynthesis, perception, signal transduction and action in plant stress response, growth and development. An update to the 2007 review in annals of botany. Ann Bot. 2013;111(6):1021-58. https://doi.org/10.1093/aob/mct067.

40. Ahammed GJ, Li X, Liu A, Chen S. Brassinosteroids in plant tolerance to abiotic stress. J Plant Growth Regul. 2020;39(4):1451-64. https://doi.org/ 10.1007/s00344-020-10098-0

41. Rajewska I, Talarek M, Bajguz A. Brassinosteroids and response of plants to heavy metals action. Front Plant Sci. 2016. https://doi.org/10.3389/fpls. 2016.00629.

42. Zehra A, Choudhary S, Wani Kl, Naeem M, Khan MMA, Aftab T. Exogenous abscisic acid mediates ROS homeostasis and maintains glandular trichome to enhance artemisinin biosynthesis in Artemisia annua under copper toxicity. Plant Physiol Biochem. 2020;156:125-34. https://doi.org/ 10.1016/j.plaphy.2020.08.048.

43. Peres A, Soares JS, Tavares RG, Righetto G, Zullo MAT, Mandava NB, Menossi M. Brassinosteroids, the sixth class of phytohormones: a molecular view from the discovery to hormonal interactions in plant development and stress adaptation. Int J Mol Sci. 2019. https://doi.org/10.3390/ ijms20020331.

\section{Publisher's Note}

Springer Nature remains neutral with regard to jurisdictional claims in published maps and institutional affiliations.
Ready to submit your research? Choose BMC and benefit from:

- fast, convenient online submission

- thorough peer review by experienced researchers in your field

- rapid publication on acceptance

- support for research data, including large and complex data types

- gold Open Access which fosters wider collaboration and increased citations

- maximum visibility for your research: over $100 \mathrm{M}$ website views per year

At BMC, research is always in progress.

Learn more biomedcentral.com/submissions 